\title{
El turisme gastronòmic: autenticitat i desenvolupament local en zones rurals
}

\author{
Francesc Fusté Forné \\ Universitat de Girona \\ researchexperiencetourism@gmail.com
}

Recepció: juny de 2014

Acceptació: gener de 2015

\section{Resum}

Un dels turismes especialitzats que està assolint més importància en l'actualitat és el gastronòmic. L'activitat agrícola i ramadera tradicional en l'àmbit del turisme rural està veient com la pràctica turística li guanya terreny. En aquest sentit, la gastronomia representa la integració dels trets característics del paisatge, tant natural com cultural, d'una destinació. Això no obstant, l'autenticitat pròpia de cada territori ha de fer front a una globalització cada vegada més ferotge, capaç de fer arribar la cuina i les formes de consum d'un costat a l'altre del món. Davant d'aquesta situació, el patrimoni culinari ha d'actuar com a font de desenvolupament local, sumant els esforços dels diferents sectors econòmics i lluitant contra l'estacionalitat de la demanda turística. Tot en un espai on els residents i els forans puguin conviure de manera sostenible.

Paraules clau: autenticitat; desenvolupament local; paisatge; turisme en espais rurals; turisme gastronòmic.

\section{Resumen. El turismo gastronómico: autenticidad y desarrollo local en áreas rurales}

Uno de los turismos especializados con mayor relevancia en la actualidad es el gastronómico. La actividad agrícola y ganadera en el ámbito del turismo rural está viendo cómo la práctica turística le gana terreno. En este sentido, la gastronomía representa la integración de los rasgos característicos del paisaje, tanto natural como cultural, de un destino. No obstante, la autenticidad propia de cada territorio debe hacer frente a una globalización cada vez más feroz, capaz de hacer llegar la cocina y las formas de consumo de un lado a otro del mundo. Ante esta situación, el patrimonio culinario debe actuar como fuente de desarrollo local, sumando los esfuerzos de los distintos sectores económicos y luchando contra la estacionalidad de la demanda turística. Todo ello en un espacio donde los residentes y los foráneos puedan convivir de manera sostenible.

Palabras clave: autenticidad; desarrollo local; paisaje; turismo en espacios rurales; turismo gastronómico. 
Résumé. Le tourisme gastronomique: authenticité et développement local dans les zones rurales

Aujourd'hui, l'une des niches touristiques spécialisées de plus grande importance est le tourisme gastronomique. Les activités traditionnelles agricoles et d'élevage dans le cadre du tourisme rural voient la pratique du tourisme gagner du terrain sur elles, et en ce sens, la gastronomie d'un lieu représente l'intégration des caractéristiques du paysage, à la fois naturelles et culturelles, d'une destination. Toutefois, l'authenticité particulière à chaque région doit faire face à la mondialisation de plus en plus féroce, capable de porter la cuisine et les modes de consommation d'un bout à l'autre du monde. Dans cette situation, le patrimoine culinaire doit agir comme source de développement local, en s'ajoutant aux efforts des secteurs économiques, et en luttant contre la saisonnalité de la demande touristique. Et ce dans un espace où les résidents et les touristes puissent cohabiter de manière durable.

Mots-clés: authenticité; développement local; paysage; tourisme dans les espaces ruraux; tourisme gastronomique.

\section{Abstract. Food tourism: Authenticity and local development in rural areas}

Food tourism has now become one of the most important specialised tourism niches. Tourism is gaining ground on traditional agricultural and livestock activities in the sphere of rural tourism. Local gastronomy reflects the integration of both the natural and cultural features of a destination. However, the authenticity of each region must deal with an increasingly fierce globalisation capable of bringing cuisine and forms of consumption from one to another side of the world. Culinary heritage must act as a source of local development by combining the efforts of economic sectors and combating seasonality in tourism demand. A balance must be sought to ensure that residents and tourists can live sustainably in a space.

Keywords: authenticity; local development; landscape; tourism in rural areas; food tourism.

\section{Sumari}

1. Introducció 4. El turisme gastronòmic com una eina

2. El turisme en espais rurals: la importància del paisatge i del patrimoni culinari

3. Gastronomia i turisme: el combat de l'autenticitat contra la globalització de desenvolupament local

5. El turisme gastronòmic com una experiència especialitzada

6. Conclusions

Referències bibliogràfiques

Every tourist is a voyeuring gourmand. (Lacy i Douglass, 2002: 8)

\section{Introducció}

Els recursos del món rural han estat, des de sempre, la base del sector primari, però ja fa unes quantes dècades que hi ha una demanda creixent cap a uns altres sectors i, en aquest sentit, el turisme ha superat l'agricultura com a activitat 
principal a la majoria de les comunitats rurals europees (Daugstad, 2008). Com més va, més clara és la relació entre l'activitat turística i les produccions agrícoles i ramaderes: «cada vegada més, les àrees rurals estan sent considerades llocs destinats a l'entreteniment, les activitats d'oci, les segones residències i com una alternativa a les àrees residencials urbanes» (Bessière, 1998: 21-28). Ara bé, la relació entre turisme i agricultura no es pot tractar només des del punt de vista de l'impacte que el sector turístic exerceix en el sector agrícola (Fleischer i Tchetchik, 2005), perquè, de retruc, la producció agrícola també beneficia la producció turística en el context del turisme rural. Sigui com sigui, hi ha diferents actors en el marc del turisme rural: d'una banda, l'agroramader i, de l'altra, el turístic, amb interessos diferents, però amb una preocupació comuna en relació amb la preservació del paisatge cultural i natural (Daugstad, 2008). Cal apreciar el quadre, és a dir, el paisatge, però també el pintor, en aquest cas, l'agricultor o el ramader. La qüestió fonamental és si els sectors del turisme i l'agricultura i la ramaderia poden treballar conjuntament amb uns objectius sostenibles (Everett i Slocum, 2013: 790). Així, una manera de continuar impulsant l'activitat primària és que els agricultors s'involucrin també en l'activitat turística (Fleischer i Tchetchik, 2005: 494), encara que, a vegades, sigui per una mera qüestió de supervivència i per complementar els ingressos provinents de les activitats tradicionals del sector primari. Sigui com sigui, aquesta relació contribueix a millorar el marc conceptual de l'enllaç existent entre turisme rural i agroramaderia, deixant palès que tots dos sectors poden treballar junts (Bowen et al., 1991); per exemple: la millora d'infraestructures no només facilita l'accés dels productes a mercats potencials, sinó que, a la vegada, permet que les persones foranes puguin viatjar i observar el paisatge rural. La promoció turística també pot centrar-se en productes agrícoles per estimular-ne la demanda exterior i, a la vegada, la promoció agrícola pot fer-ho en el paisatge regional per ajudar la demanda turística a créixer (Bowen et al., 1991: 49). Encara que, també, «el desenvolupament de les comunicacions, a la vegada amb millores significants pel que fa a la productivitat $\mathrm{i}$ als sistemes de producció, ha contribuiit àmpliament a obrir les àrees rurals al món exterior» (Bessière, 1998: 22). En aquest sentit, «el turisme gastronòmic pot ser una de les oportunitats alternatives per als productors d'aliments, especialment a les àrees rurals, per afegir valor als seus productes» (Quan i Wang, 2004: 303), tenint en compte el medi físic i el medi humà alhora.

\section{El turisme en espais rurals: la importància del paisatge i del patrimoni culinari}

El turisme rural és considerat crucial en la política agrícola, en la mesura que aquesta vol reestructurar i crear o mantenir llocs de treball a les àrees rurals (Cànoves et al., 2004: 759), i això és també gràcies al fet que el turisme rural manté la simbiosi entre la producció agrícola i la conservació d'un entorn rural cada vegada més humanitzat. Així, el turisme rural no es pot circumscriure únicament al concepte d'allotjament, ja que «la millora de les 
característiques úniques de cada àrea requereix el desenvolupament de les activitats inherents al territori» (Cànoves et al., 2004: 766), entre les quals es troba la gastronomia local. El cultiu de la terra, el manteniment de les explotacions, la restauració dels edificis, entre altres, formen part del patrimoni cultural de les zones rurals: no hi ha atracció turística sense un estil de vida pròpiament campestre. D'altra banda, Urry (1990) afirma que ha sorgit un nou consumidor que sent que ha perdut les seves arrels, perquè, tal com diu Pearce (1990), l'atracció universal del turisme rural resta en els esdeveniments ordinaris i quotidians de la seva comunitat: «les àrees rurals, en contraposició a les urbanes i només ocupades per la flora i la fauna, representen l'oportunitat de conèixer les formes de vida locals i el contacte amb els residents, la qual cosa atorga un rol especial a l'experiència de turisme rural» (Lane, 1994). Així, els entorns rurals constitueixen l'oportunitat d'establir contacte amb la naturalesa i la cultura, de tornar al que és autèntic, a un ambient diferent, $\mathrm{i}$ sense els factors d'estrès de les àrees urbanes (la contaminació, les aglomeracions, el soroll o els horaris atapeïts), amb la qual cosa contribueixen també a promoure la desestacionalització de l'activitat turística.

En entorns rurals, i específicament en àrees de muntanya, «a qualsevol lloc on mirem, estem envoltats de paisatge. La manera com es configura el paisatge és el resultat d'una sèrie de decisions. La terra cultivada proporciona aliments, i el paisatge cultural influenciat per l'agricultura és d'una gran importància per al turisme, el patrimoni cultural i la identitat, l'oci i el benestar, com també per mantenir la diversitat» (Daugstad, 2008: 417). Segons Díaz i Llurdés (2013: 75), «quan tota una comunitat identifica una sèrie d'elements tangibles $\mathrm{i}$ intangibles $\mathrm{i}$ els reconeix com a propis i únics, aquests configurarien el seu paisatge, un marc que no existeix enlloc més». El paisatge, que es viu a través dels cinc sentits, és un factor imprescindible per al turisme rural i un exemple de com els propis agricultors i ramaders veuen el seu paper en relació amb la combinació d'agricultura i turisme. Així, la cadena completa de processos que intervenen en la producció de la llet, les verdures, els productes de la terra al plat no pot ser observada en un sol espai (Hjalager, 1996: 108). Una resposta innovadora consisteix a reinventar tradicions a través, per exemple, de la creació de productes agrícoles o de botigues que ofereixin experiències pràctiques on els turistes participin en la cocció, la teixidura, el munyiment $i$ altres activitats (Daugstad, 2008: 421). En aquest sentit, el patrimoni culinari està profundament arrelat a un lloc en particular, així com a un espai i a un temps concrets, de manera que les tradicions culinàries són un element identificador de pobles i territoris, i revelen el caràcter de la societat i la mentalitat dels membres d'una àrea específica (Bessière, 1998; Feo, 2005).

El patrimoni culinari que es troba a les àrees rurals es correspon a la memòria d'un grup sencer, a les seves arrels, i genera un sentiment de pertinença a una àrea particular (Bessière, 1998), tal com es veia unes línies més amunt. D'aquesta manera, la promoció o la valorització d'aquest patrimoni ha d'encoratjar les iniciatives locals, individuals i col-lectives, i és vist com un procés per promoure el desenvolupament del turisme rural, vinculat, així, 
a la filosofia slow, a un turisme de proximitat que aprofita les potencialitats inherents a un territori (Díaz i Llurdés, 2013), a partir de la reivindicació del que és local. Se'n troba un exemple a la recuperació d'una tradició mil.lenària en l'elaboració del laguiole, un formatge local francès, a través de la creació de la Coopérative Fromagère Jeune Montagne, l'any 1960, per preservar la maquinària original i promocionar el producte d'aquesta ciutat homònima; perquè, a França, el patrimoni culinari s'hi aprecia ja des de l'any 1980, amb la distinció dels sites remarquables du goût (Bessière, 1998). La gastronomia, i també el vi, són un aspecte de l'estil de vida d'un territori i exerceixen una poderosa influència pel que fa a un sentiment d'implicació i d'identificació amb aquest (Henderson, 2009: 318-323). Perquè els productes frescos que s'ofereixen en aquests mercats agrícoles atrauen, a la vegada, turistes i locals. Sigui com sigui, «el consum de l'espai implica l'apreciació de la idiosincràsia de cada territori, i les zones de turisme rural són especialment riques en cultura, diversitat de paisatges, gastronomia i tradicions» (Cànoves et al., 2004: 767). La comunitat local té, per tant, un rol actiu en la creació de l'experiència turística, la qual cosa ajuda les persones foranes a descobrir una experiència més intensa dels llocs i a gaudir-ne, a la vegada que en beneficia el propi desenvolupament. Els residents comparteixen el seu coneixement de la història de la regió, la cultura i el patrimoni natural, i poden oferir oportunitats d'establir un contacte més proper amb la seva manera de viure (rebent els turistes a casa seva) o amb els productes locals (oferint-los-els) (Kastenholz et al., 2012: 208). Segons Daugstad (2008: 413): «el turista modern vol l'experiència personal de tastar, sentir i escoltar històries sobre el paisatge, experimentar-ho de primera mà», perquè la gastronomia és un dels ingredients més importants de l'oferta d'una destinació.

\section{Gastronomia i turisme: el combat de l'autenticitat contra la globalització}

McNeill (1974) exposa la noció de la relació natural entre el territori, les seves condicions climàtiques i el caràcter de la gastronomia que produeix. És aquesta diversitat geogràfica la que proveeix la distinció regional en referència a les tradicions culinàries i l'evolució d'un patrimoni característic. I és servint-se de valors com l'autenticitat, la identitat cultural o l'etnicitat que s'aconsegueix convertir l'espai i el patrimoni rural per fer-ne un ús turístic (Cànoves i Villarino, 2000). Això no obstant, segons Belisle (1983), els turistes solen preferir aliments similars als que troben als seus propis països, $\mathrm{i}$ això facilita la globalització i dificulta la promoció dels productes propis dels llocs on viatgen. «Per què la temptació del que és llunyà sol eclipsar el paisatge del que és quotidià?» (Díaz i Llurdés, 2013: 84). Segons Norberg (2006), l’homogeneïtzació de la cultura ha implicat un menyspreu cap allò que ens és més proper, a la vegada que ha promogut un desig cada vegada més gran cap allò que ens és llunyà. Així, actualment, és clara la tendència a l'estandardització, a la coca-colaïtzació, que posa en perill la integritat de les cultures (Hughes, 1995), perquè hi ha 
una tendència cap a l'homogeneïtzació universal, per exemple, mitjançant l'expansió de les cadenes de menjar ràpid (Alfino et al., 1998). Sota l'amenaça d'aquesta homogeneïtzació global impulsada pel consum, i que connecta totes les audiències del món a través dels mitjans de comunicació, l'autenticitat ha de representar una manifestació de la integritat territorial (Hughes, 1995: 784). D'aquesta manera, la força de la globalització és comunament vista com una amenaça per la relació pròxima entre gastronomia i territori, a la vegada que, en conseqüència, representa també una amenaça per la identitat gastronòmica local i la imatge que pot mostrar (Mak et al., 2012). Avui en dia, s'observa, doncs, una mcdonaldització que fa que les samoses siguin ara menjar anglès igual que la pizza és americana i el curri indonesi és típic d'Holanda. Però el sandvitx ràpid i el Big Mac estan mancats de tradició i d'identitat (Bessière, 1998). "Fins i tot quan el toc del que és exòtic i la uniformitat del que és local són més intensos, es pot menjar internacionalment - menjar mexicà a Noruega, etíop a Itàlia» (Calhoun, 2002: 889). Per bé o per mal, el turisme és un vehicle que promou la globalització.

Afortunadament, en una part de la demanda turística, es produeix un canvi que té a veure amb la consciència gastronòmica. «La cuina amb un toc de país i els productes naturals han augmentat la seva popularitat» (Bessière, 1998: 24): pa cuit en forns de pedra o productes frescos, entre altres. «La vida camperola s'ha convertit en el santuari d'origen de les persones, de les seves arrels perdudes i en la font d'una autenticitat improbable» (Burguière et al., 1993). En consumir un producte natural, o tradicional, aquell que se'l menja incorpora, a més de les característiques nutritives dels aliments, unes qualitats simbòliques: «ens apropiem de la naturalesa, la cultura i la identitat d'una zona. També representa la integració en un món social en contraposició amb l'univers d'aliments industrialitzats. Menjar productes frescos de granja, per exemple, pot representar, per al turista urbà, no només gaudir d'una qualitat biològica, sinó també fer una apropiació efímera de la identitat rural» (Bessière, 1998: 25). Cal lluitar contra la globalització emfatitzant la unicitat de la cultura gastronòmica local i la seva identitat, el sense of place, que representa un important factor d'atracció (Scarpato, 2002). Per exemple, a Hong Kong, l'estil de te anglès ha evolucionat en un nou estil local de beure, perquè, en la preparació del te amb llet, s'usa llet evaporada en comptes de llet fresca. Una altra beguda comuna consumida als cafes locals és el yuan-yang, que consisteix en una barreja de te i cafe. Totes dues begudes s'han convertit en productes alimentaris glocals d'èxit (Mak et al., 2012). Una iniciativa glocal que ha sorgit a Catalunya recentment és la del butipà, que utilitza la idea de l'entrepà com un concepte del menjar ràpid, però elaborat amb productes de la terra.

L'autenticitat de la gastronomia inclou inevitablement un component geogràfic i cultural. Tal com afirmen Hillel et al. (2013: 202), el component natural dóna a la gastronomia les condicions físiques pròpies i úniques de cada territori, $\mathrm{i}$ el component cultural li confereix els valors compartits pels membres de la comunitat local. Els dos components transformen la gastronomia en un bé patrimonial material que parteix de la identitat cultural, n’assegura la continuïtat i dóna fe 
del compromís adquirit amb el territori. «Les destinacions gastronòmiques d'èxit són, en conseqüència, aquelles que sacien l'apetit dels turistes gastronòmics per l'autenticitat, oferint productes i experiències que comuniquen fidelment un vincle proper entre gastronomia, territori i comunitat» (Hillel et al., 2013: 202). $S$ 'ha d'entendre la unicitat i la rellevància d'alguns productes locals (per exemple: el formatge, el pa o el vi, entre molts altres) que, quan són presentats com a experiències, mostrant-ne el procés de producció d'una forma atractiva i potser fins $\mathrm{i}$ tot permetent als turistes que hi participin, se'ls atorga autenticitat (Wang, 1999). El concepte de gastronomia tradicional, per exemple en zones de muntanya, pot augmentar-ne l'atracció si es comercialitza el fet que es pot menjar exactament el mateix plat que es va servir al primer excursionista, al primer viatger o al primer escriptor que hi va anar (Lauritzen, 2003), «la qual cosa es pot veure com un producte de nostàlgia, mentre que el producte gourmet és una barreja moderna típica del que és local i el que és global que dóna com a resultat la gastronomia glocall (Daugstad, 2008: 416), com es deia al paràgraf anterior.

La gastronomia en les destinacions és una de les últimes àrees d'autenticitat (Reynolds, 1994; Torres i Pulido, 2009), i el que fa la gastronomia és oferir «una autèntica mossegada del territori» (Hillel et al., 2013: 202), perquè és un forjador poderós de la identitat cultural (Fischler, 1980, 1988). Es tracta d'exposar el turista a una autèntica experiència culinària, que se senti involucrat en la construcció d'una identitat cultural en un entorn natural únic, com passa, per exemple, en el cas de la Vall de Boí, als Pirineus, i en el marc del Parc Nacional d'Aigüestortes i Estany de Sant Maurici. Així, en un estudi realitzat sobre el cas de la Vall de Boí com a destinació turística gastronòmica (Fusté, 2014b), s'hi mostra com es configura la gastronomia als Pirineus catalans i com aquesta es troba fortament marcada per les estacions de l'any, moduladores del paisatge i el territori, de manera que és imprescindible associar aquest paisatge canviant amb les menges pròpies de cada època. En conseqüència, s'observa el lligam indissoluble de la gastronomia amb el cicle natural de la terra (Moyes, 2010).

\section{El turisme gastronòmic com una eina de desenvolupament local}

En la relació entre el turisme i l'agricultura i la ramaderia, «és insuficient establir metes simplement en termes de nombre de visitants o en relació amb la seva despesa turística, ja que, si les oportunitats de treball i els ingressos no arriben als residents locals, aquests perden més del que guanyen amb el desenvolupament del turisme» (Telfer i Wall, 1996: 650). Així, hi ha diversos autors que reconeixen els beneficis del turisme gastronòmic com una àncora per afavorir el desenvolupament regional (Bèssiere, 1998; Hall et al., 2003; Hjalager i Richards, 2002; Millán et al., 2014). Dins del turisme cultural, el turisme gastronòmic també ha de servir com una eina de desenvolupament local, establint, com es deia unes quantes línies més amunt, una connexió entre gastronomia, territori i comunitat, perquè el turisme gastronòmic s'estén més enllà d'una col-lecció d'especialitats gastronòmiques o d'establiments d'aliments de 
qualitat, per incloure-hi productes i experiències que encapsulen els factors humà i geogràfic propis d'una destinació (Hillel et al., 2013: 208), el component cultural i el natural (Tresserras, 2009). A la vegada, el turisme gastronòmic com a eina de desenvolupament rural ha d'ajudar a protegir el medi (Henderson, 2009: 321; Millán et al., 2014).

És ben clar que el desenvolupament del turisme permet, a la vegada, millorar les infraestructures $i$, de retruc, beneficiar el sector agrícola, com es veia al principi, però és facil trobar també que molts agricultors fallen a l'hora d'ajustar la seva producció com una resposta a les necessitats especials d'una indústria turística creixent, i això fa que no se'n beneficiïn. Per tant, ajustar l'activitat o els horaris a les necessitats dels visitants és el que fa perdre l'essència de l'activitat tradicional. En entorns rurals i de muntanya, els establiments solen ser empreses familiars on poques persones ho fan tot - reserves, atenció de trucades o servei al visitant-, a més de continuar realitzant la feina de tota la vida. Però ha de ser al revés, cal donar prioritat a l'activitat agrícola $\mathrm{o}$ ramadera, i l'activitat turística n'ha d'esdevenir una conseqüència, per tal que pugui ser aprofitada com una autèntica eina de desenvolupament local, com es veu també a Díez (2012) i a Torres i Pulido (2009). Així, s'observa el creixement de nínxols de mercat que revaloritzen els aliments artesanals identificats geogràficament: França i Itàlia, com també Espanya, són els països en els quals aquesta tendència s'observa més clarament (Barrera, 1999; Henderson, 2009).

Els elaboradors de productes gastronòmics veuen, en la qualitat i en l'assegurament de la qualitat, "una eina de màrqueting per augmentar les vendes» (Hughes, 1995: 793). Però, realment ho volen? El que sí que està clar és que cada vegada trobem més consumidors que mostren un interès creixent en tots dos aspectes per diverses raons, tal com enumera el propi Hugues (1995): una preocupació que augmenta sobre la seguretat en relació amb els productes gastronòmics; un interès creixent pel medi ambient $i$ pel benestar animal en relació amb les conseqüències dels mètodes de producció, i, a la vegada, una demanda creixent de productes gastronòmics de qualitat, dels quals valoren tant termes d'aparença, com de frescor, sabor, textura o qualsevol altra excel-lència percebuda. Així, es considera cabdal el procés de producció, elaboració i control dels productes i dels mitjans per tal de mantenir els valors tradicionals i permetre'n el desenvolupament sense deteriorar els recursos que el fan possible (Fusté, 2014a). Es tracta d'aliments regionals que es distingeixen per aspectes de qualitat o per un cert nivell de sofisticació, ja sigui «per la novetat que mostren en el mercat, pel packaging o per la vinculació amb regions de l'interior que contenen algun atractiu natural o cultural per als consumidors" (Barrera, 1999: 5). Segons el mateix autor, «els aliments produïts sota patrons de qualitat certificables basen la seva estratègia de penetració en el mercat i la seva identitat, en una relació privilegiada i de respecte pel medi ambient $\mathrm{i}$ la cultura regional» (Barrera, 1999: 6). Així, el gaudi pels productes autòctons $i$ la marca $\mathrm{i}$ el valor afegit que es genera, per exemple, amb els productes amb denominació d'origen representen, també, un factor molt important per al desenvolupament econòmic regional (Bigné, 2011), amb la qual cosa se situa 
la qualitat en la producció en un territori específic (Tresserras i Medina, 2008). En aquest context, la clau de l'èxit és integrar el que és natural, el que és local i el que és tradicional (MacDonald, 2013), en una clara referència als desitjos del consumidor que aprecia un consum alimentari associat a una identitat, a un paisatge.

\section{El turisme gastronòmic com una experiència especialitzada}

Segons Kastenholz et al. (2012: 212), la manera com l'experiència vinculada al turisme rural és oferta representa un repte per a la comunitat local en la seva cerca d'identitat, així com pel que fa a noves oportunitats de desenvolupament, tant per als proveïdors locals de turisme rural, en la generació d'un benefici també sostenible, com pels turistes, en la cerca d'experiències autèntiques i significants. En aquest sentit, la gastronomia esdevé un component fonamental del viatge: menjar és una part integral de les vacances, i l'entorn rural representa una apropiació de la història local en termes d'hàbits alimentaris (Bessière, 1998). El turisme gastronòmic és definit com aquell desig d'experimentar un tipus de gastronomia particular d'una regió específica (Hall i Sharples, 2003: 10), $\mathrm{i}$ aquest turisme gastronòmic es pot experimentar des de dos sectors diferents: l'agricultura i el turisme (Everett i Slocum, 2013). Així, la rellevància de la gastronomia en l'activitat turística és tan clara com que tots els turistes han de menjar en algun moment durant el viatge (Richards, 2002). De fet, tenen en l'alimentació una de les despeses principals quan es desplacen: més d'un terç del total (Belisle, 1983; Hall i Sharples, 2003; Telfer i Wall, 1996, 2000), i aquesta despesa en alimentació no inclou només el consum pròpiament dit, sinó també l'adquisició de productes alimentaris locals com si fossin souvenirs (Henderson, 2009: 318). Així, la literatura existent sobre gastronomia i turisme revela diversos punts importants. Segons Mak et al. (2012: 176): és essencial, ja que els turistes necessiten menjar quan viatgen; pot tenir lloc en contextos desconeguts pel que fa a aliments $\mathrm{i}$ a hàbits alimentaris; és de caràcter temporal; implica un significat simbòlic, i s'associa amb la motivació turística.

Un model útil per conceptualitzar l'experiència en el turisme gastronòmic és el que estableixen Quan i Wang (2004: 301), que diferencien entre dues perspectives: l'una, la seva relació amb l'experiència turística cim i, l'altra, la vinculació que presenta amb l'experiència diària. El comportament del turista que només cerca un canvi en relació amb la rutina i aquell que cerca la novetat es diferencien l'un de l'altre en el fet que el segon es refereix a la situació en la qual les persones són capaces de tastar aliments que encara no coneixien (Quan i Wang, 2004). Així, segons Long (1988: 181), els turistes gastronòmics són aquells que es defineixen per participar en els costums alimentaris de l'altre de manera intencional $i$ exploratòria. Les experiències vinculades al turisme gastronòmic, doncs, consisteixen en dos tipus: primer, quan els ingredients del menjar són nous; segon, quan ho és la manera de servir o de consumir. Per exemple, a la Xina, l'arròs es cuina normalment en una cassola o en una olla d'arròs elèctrica; ara bé, en algunes zones turístiques com ara, per exemple, 
Jiangxi, l'arròs que se serveix als turistes es cou en bambú (Quan i Wang, 2004), la qual cosa representa una manera diferent de viure la mateixa experiència. Així, aquesta experiència gastronòmica pot ser, a la vegada, cim o també una extensió de la vida quotidiana (Mkono et al., 2013). Per tant, dues persones poden experimentar cada una de les dimensions davant un mateix plat, la diferència es troba en si una ja l'havia tastat abans o no. El rol de la gastronomia pot esdevenir repetitiu i rutinari en la vida diària de cada individu, però augmenta la seva importància quan hi ha situacions noves, inusuals i estranyes com les que els turistes troben en un viatge (Cohen i Avieli, 2004: 758). Ara bé, hi ha una puntualització que cal afegir-hi: els aliments i les begudes estranyes poden representar un risc potencial per al cos; les escenes poc habituals, no. És a dir, mentre una escena o un paisatge que no ens agradi es pot treure del programa de viatge si és poc atractiu, no es pot evitar menjar o beure. Per tant, hi ha una tensió constant entre l'atracció i el rebuig a la novetat gastronòmica, a la novetat o a la familiaritat dels aliments i dels hàbits alimentaris (Cohen i Avieli, 2004: 775; Mak et al., 2012), tal com es veia unes línies més amunt.

Sigui com sigui, la gastronomia és un atractiu important des del punt de vista turístic i representa un factor decisiu a l'hora de decidir un viatge. Sense anar més lluny, gairebé el 10\% dels turistes internacionals que van visitar Espanya l'any passat van declarar que la qualitat de l'alimentació i dels vins era el motiu principal d'haver triat aquesta destinació (Diputació de Lleida, 2013). Segons Flavian i Fandos (2011: 12): «caldria destacar que la gastronomia s'està convertint en una motivació de viatge cada vegada més important en els nostres dies. De fet, actualment, visiten Espanya per aquest motiu fonamentalment al voltant de cinc milions i mig de persones cada any. A més, la gran majoria dels cinquanta milions de turistes estrangers que van venir a Espanya destacaren l'atractiu de la seva gastronomia quan se'ls preguntà sobre els aspectes més valorats del país». Dades com aquestes demostren la importància de la motivació per la gastronomia, perquè «ofereix plaer i entreteniment» (Henderson, 2009: 317). Una de les motivacions dels turistes és tastar aliments, la qual cosa inclou, doncs, el turisme gastronòmic pròpiament dit, però també festivals gastronòmics, turisme enològic $\mathrm{i}$ altres esdeveniments relacionats amb el menjar i la beguda (Everett i Slocum, 2013: 791). Això significa que aquests elements són, per si sols, una atracció turística, com passa amb el Taste of Chicago, el Festival de l'Espàrrec a Stockton (California), els festivals de la xocolata britànics o els tours enològics arreu d'Europa, entre molts i molts altres. En el cas de Catalunya, destaquen els programes d'enoturisme i oleoturisme impulsats per l'Agència Catalana de Turisme i la Generalitat de Catalunya, iniciatives per afavorir el desenvolupament econòmic territorial i fomentar el desenvolupament turístic en base als productes de qualitat i l'elaboració que comporten. També hi trobem les festes del vi o les fires de la fruita (maduixa, cirera o pera) de Lleida, a més d'altres jornades temàtiques al voltant de productes autòctons com ara el mateix oli, el formatge o els bolets, per citar-ne alguns exemples. De rellevància internacional, cal citar també la candidatura Vic-Osona com a ciutat UNESCO de la Gastronomia o la participació de la cooperativa Falset- 
Marçà en una ruta turística europea, amb l'objectiu de promoure la riquesa del patrimoni cultural i industrial de la regió. En tots aquests casos, els aliments constitueixen una atracció per a les persones foranes, «no menys significant que altres atraccions com ara el paisatge o un parc temàtic» (Quan i Wang, 2004: 302).

L'experiència gastronòmica cada vegada està adquirint més ressò a nivell internacional i també gràcies a la promoció que se'n fa a través dels mitjans de comunicació. Dins del turisme gastronòmic, l’enoturisme (Díez, 2012; Millán et al., 2014) és un dels més consolidats a escala global; a països com ara França, Itàlia, Espanya, Portugal, Regne Unit, Bulgària, Romania i Hongria a Europa, i també als Estats Units, Austràlia, Nova Zelanda, Canadà i Sud-àfrica (Hall, 2004). I és que el significat de la gastronomia es pot donar en aquesta mateixa com a símbol —en el cas del vi-, com a signe de comunió — la funció social de compartir-, com a marcador de classe — en el consum diari- i com a emblema - el patrimoni culinari identificador d'una àrea o d'una comunitat- (Bessière, 1998: 23). D'aquesta manera, els productes alimentaris, les especialitats culinàries o les rutes gastronòmiques, així com també els festivals gastronòmics, són algunes de les fonts principals que ajuden a promocionar la identitat local de la destinació (Everett i Aitchison, 2008; Feo, 2005; Millán et al., 2014; Royo, 2011; Torres i Pulido, 2009) i on la participació de la comunitat local esdevé imprescindible perquè la combinació de gastronomia i turisme sigui sostenible (Quan i Wang, 2004). És evident, però, que la gran quantitat de productes que es deriven del turisme gastronòmic també genera una lògica problemàtica: gastronomia i turisme encara han de crear una col-laboració viable (Everett i Slocum, 2013: 806). En definitiva, el desenvolupament i la promoció de productes gastronòmics ha de contribuir a facilitar la "posada en valor dels recursos naturals i culturals de l'interior del país, al mateix temps que promoure el respecte pel medi ambient i la cultura rural» (Barrera, 1999: 10).

\section{Conclusions}

La literatura creixent referent a la vinculació de la gastronomia amb el turisme en diferencia diversos àmbits: la gastronomia com un producte o una atracció turística, el comportament de la gent forana en relació amb el consum d'aliments i l'interès que mostra pel menjar i la beguda, com també per qualsevol esdeveniment $\mathrm{i}$ activitat que hi estiguin relacionats. Aquest últim és el que més clarament representa la gastronomia com a motivació principal de viatge (Mak et al., 2012). Segons Kivela i Crotts (2006), menjar és una pràctica única dins l'activitat turística, perquè gratifica els cinc sentits. «Aquell que menja es converteix en part d'una cultura. Tant el menjar com la cuina, ja que estan determinades culturalment, col-loquen aquell qui menja en un univers social i en un ordre cultural» (Bessière, 1998: 24). Així, la dieta d'un habitant d'una ciutat contrasta amb els hàbits alimentaris tradicionals: «l'anonimat de l'alimentació actual és el resultat de la industrialització nutritiva, menys àpats estructurats, entrepans improvisats, un llegat culinari empobrit i una 
escletxa més gran entre l'agricultor i el consumidor» (Bessière, 1998: 24). Això permet retornar a la complexitat de la relació entre turisme i agricultura, ja que aquesta relació «s'ha d'emmarcar dins el concepte de desenvolupament turístic sostenible» (Telfer i Wall, 1996: 643), tenint en compte que «el mercat dels aliments constitueix una unitat que s'inicia al camp, continua a la indústria i arriba als consumidors" (Barrera, 1999: 4), amb la qual cosa toca els tres sectors econòmics.

Segons Padín (2009), un dels productes turístics que exerceix més impacte en la cultura i en la identitat d'una destinació turística és la seva gastronomia. En aquest sentit, per augmentar l'impacte positiu d'aquesta activitat, també s'ha d'incrementar la quantitat de menjar local utilitzat en la indústria turística (Telfer i Wall, 1996), amb «aliances estratègiques que exhibeixin els productes alimentaris locals» (Henderson, 2009: 319), combinant iniciatives públiques i privades amb rutes gastronòmiques, visites als centres de producció o creació de museus, per exemple. Aquesta diversificació no està únicament dirigida als turistes, de manera que els residents també són uns consumidors reals i potencials importants d'aquests productes gastronòmics: «molts restaurants i esdeveniments depenen del suport local, la qual cosa ajuda a alleugerir les conseqüències adverses d'una arribada estacional de turistes» (Henderson, 2009: 320). És el problema de l'estacionalitat en espais rurals, en general, i en zones de muntanya, en particular, ja que es produeix una demanda concentrada durant els caps de setmana i els períodes tradicionals de vacances (Cànoves et al., 2004: 767), i aquesta estacionalitat del turisme també afecta el sector primari.

L'activitat turística és extremament competitiva, amb una lògica rivalitat entre destinacions, i això n'inclou també l'aspecte gastronòmic: «la singularitat local ha de ser, per tant, identificada i emfatitzada, utilitzant la gastronomia com un mitjà de posicionament i diferenciació en la promoció» (Henderson, 2009: 322). El turista busca el que és local, diferent del que està acostumat a viure i a veure, però també cerca allò que no s'ha creat específicament per a ell com a turista, i la gastronomia compleix totes dues característiques (Tresserras i Medina, 2008). Així, «l'evolució de l'espai rural se centra en la vinculació de l'oferta turística als productes locals i a la tradició culinària» (Bessière, 1998). Segons la mateixa Bessière (1998: 30), «la gastronomia és un factor d'atracció turística, integració i dinamització social», que representa la suma de tots els elements que formen el paisatge global d'un territori i que els residents i els forans han de compartir de manera sostenible.

\section{Referències bibliogràfiques}

Alfino, M.; Caputo, J. i Wynyard, R. (1998). McDonaldization Revisited: Critical Essays on Consumer Culture. Westport: Praeger.

BARRERA, E. (1999). «Las rutas gastronómicas: Una estrategia de desarrollo rural integrado». IV Seminario Internacional de Turismo Rural del Cono Sur. Santiago de Chile. 
Belisle, F. J. (1983). "Tourism and Food Production in the Caribbean». Annals of Tourism Research, 10, 497-513. <http://dx.doi.org/10.1016/0160-7383(83)90005-1>

Bessière, J. (1998). «Local development and heritage: Traditional food and cuisine as tourist attractions in rural areas». Sociologia Ruralis, 38 (1), 21-34. <http://dx.doi.org/10.1111/1467-9523.00061>

Bigné, E. (2011). "Las respuestas del turista ante la imagen del lugar de origen del producto". A: Flavian, C. i Fandos, C. (coords.). Turismo gastronómico: Estrategias de marketing y experiencias de éxito. Saragossa: Prensas Universitarias, 51-68.

Bowen, R L.; Cox, L. J. i Fox, M. (1991). «The Interface between Tourism and Agriculture». Journal of Tourism Studies, 2, 43-54.

Burguière, A.; Fabre, D. i Plessis, A. (1993). "L'héritage». A: Burguière, A. i Revel, J. (eds.). Histoire de la France: Les formes de la culture. París: Seuil.

Calhoun, C. (2002). "The class consciousness of frequent travelers: Toward a critique of actually existing cosmopolitanism». The South Atlantic Quarterly, 101 (4), 869-897. <http://dx.doi.org/10.1215/00382876-101-4-869>

Cànoves, G. i Villarino, M. (2000). «Turismo en espacio rural en España: Actrices e imaginario colectivo». Documents d'Anàlisi Geogràfica, 37, 51-77.

Cànoves, G.; Villarino, M.; Priestley, G. K. i Blanco, A. (2004). «Rural tourism in Spain: An analysis of recent evolution». Geoforum, 35, 755-769. <http://dx.doi.org/10.1016/j.geoforum.2004.03.005>

Cohen, E. i Avieli, N. (2004). «Food in Tourism: Attraction and Impediment». Annals of Tourism Research, 31 (4), 755-778. <http://dx.doi.org/10.1016/j.annals.2004.02.003>

Daugstad, K. (2008). "Negotiating landscape in rural tourism». Annals of Tourism Research, 35 (2), 402-426. <http://dx.doi.org/10.1016/j.annals.2007.10.001>

DíAz, I. i Llurdés, J. C. (2013). «Reflexiones sobre el turismo de proximidad como una estrategia para el desarrollo local». Cuadernos de Turismo, 32, 65-88.

Díez, D. (2012). "Los turismos de interior: Un enfoque desde la dimensión de las modalidades turístico-recreativas». Documents d'Anàlisi Geogràfica, 58 (3), 373-396.

Diputació de Lleida (2013). Pla Operatiu de Turisme de Lleida 2014. Lleida: Ara Lleida. Diputació de Lleida.

Everett, S. i Aitchison, C. (2008). "The role of food tourism in sustaining Regional identity: A Case study of Cornwall, South West England. Antecedents of consumer commitment to a PDO wine: An empirical analysis of Spanish consumers». Journal of Sustanaible Tourism, 16 (2), 150-167. <http://dx.doi.org/10.2167/jost696.0>

EveretT, S. i Slocum, S. L. (2013). «Food and tourism: an effective partnership?: A UK-based review». Journal of Sustanaible Tourism, 21 (6), 789-809. <http://dx.doi.org/10.1080/09669582.2012.741601>

Feo, F. (2005). «Turismo gastronómico en Asturias». Cuadernos de Turismo, 15, 77-96.

Fischler, C. (1980). «Food habits, social change and the nature/culture dilemma». Social Science Information, 19 (6), 937-953. <http://dx.doi.org/10.1177/053901848001900603> 
- (1988). «Food, self and identity». Social Science Information, 27 (2), 275-292. <http://dx.doi.org/10.1177/053901888027002005>

Flavian, C. i Fandos, C. (coords.) (2011). Turismo gastronómico: Estrategias de marketing y experiencias de éxito. Saragossa: Prensas Universitarias.

Fleischer, A. i TCHeTchiк, A. (2005). «Does rural tourism benefit from agriculture?». Tourism Management, 26, 493-501.

<http://dx.doi.org/10.1016/j.tourman.2003.10.003>

Fusté Forné, F. (2014a). «Simbiosi entre agroramaderia i turisme: La indústria formatgera a la comarca del Pallars Sobirà». A: Boyra, J.; Fusté, F. i Molleví, G. (coords.). Creació i comercialització de productes turístics. Barcelona: Escola Universitària Formatic Barcelona, 125-133.

- (2014b). «L'autenticitat en el patrimoni gastronòmic: La Vall de Boí com a destinació turística gastronòmica». 3rd International Congress UNITWIN Network UNESCO Chair "Culture, Tourism, Development» on "Tourism and Gastronomy Heritage - Foodscapes, Gastroregions and Gastronomy Tourism». Barcelona.

Hall, C. (2004). Wine, Food and Tourism Marketing. Nova York: The Haworth Hospitality Press.

Hall, C. i Sharples, E. (2003). «The consumption of experiences or the experience of consumption?: An introduction to the tourism of taste». A: Hall, C. M.; Sharples, E.; Mitchell, R.; Macionis, N. i Cambourne, B. (eds.). Food tourism around the world: Development, management and markets. Oxford: Butterworth Heinemann, 1-24.

Hall, M.; Sharples, L.; Mitchell, R.; Macionis, N. i Cambourne, B. (2003). Food tourism around the world: Development, management, and markets. Oxford: Butterworth-Heinemann.

Henderson, J. C. (2009). «Food tourism reviewed». British Food Journal, 111 (4), 317-326. <http://dx.doi.org/10.1108/00070700910951470>

Hillel, D.; Belhassen, Y. i Shani, A. (2013). «What makes a gastronomic destination attractive?: Evidence from the Israeli Negev». Tourism Management, 36, 200-209. <http://dx.doi.org/10.1016/j.tourman.2012.12.006>

Hjalager, A. (1996). "Agricultural diversification into tourism: Evidence of a European Community development programme». Tourism Management, 17, 103-111. <http://dx.doi.org/10.1016/0261-5177(95)00113-1>

Hjalager, A. i Richards, G. (2002). Tourism and gastronomy. Londres: Routledge.

Hughes, G. (1995). "Authenticity in Tourism». Annals of Tourism Research, 22 (4), 781-803. <http://dx.doi.org/10.1016/0160-7383(95)00020-x>

Kastenholz, E.; Carneiro, M. J.; Marques, P. C. i Lima, J. (2012). «Understanding and managing the rural tourism experience: The case of a historical village in Portugal». Tourism Management Perspectives, 4, 207-214.

<http://dx.doi.org/10.1016/j.tmp.2012.08.009>

Kivela, J. i Crotts, J. (2006). «Tourism and gastronomy: Gastronomy's influence on how tourists experience a destination". Journal of Hospitality and Tourism Research, 30 (3), 354-377. <http://dx.doi.org/10.1177/1096348006286797>

Lacy, J. i Douglass, W. (2002). «Beyond Authenticity: The Meaning and Uses of Cultural Tourism». Tourist Studies, 2, 9-21. <http://dx.doi.org/10.1177/1468797602002001094> 
LANE, B. (1994). «Sustanaible rural tourism strategies: A tool for development and conservation». Jounal of Sustanaible Tourism, 2 (1), 102-111. <http://dx.doi.org/10.1080/09669589409510687>

Lauritzen, P. (2003). «Levende mattradisjoner på Mogen». Fjell og Vidde, 5, 52-55.

Long, L. (1998). "Culinary tourism: a folkloristic perspective on eating and otherness». Southern Folklore, 55 (3), 181-204.

Macdonald, K. I. (2013). "The morality of cheese: A paradox of defensive localism in a transnational cultural economy». Geoforum, 44, 93-102. <http://dx.doi.org/10.1016/j.geoforum.2012.03.011>

Mak, A. H.; Lumbers, M. i Eves, A. (2012). «Globalisation and Food Consumption in Tourism». Annals of Tourism Research, 39 (1), 171-196. <http://dx.doi.org/10.1016/j.annals.2011.05.010>

McneILl, F. (1974). The Scots Kitchen: Its Lore and Recipes. St. Albans: Mayflower Books.

Millán, G.; Morales, E. i Pérez, L. M. (2014). «Turismo gastronómico, denominaciones de origen y desarrollo rural en Andalucía: Situación actual». Boletín de la Asociación de Geógrafos Españoles, 65, 113-137.

Mkono, M.; Markwell, K. i Wilson, E. (2013). "Applying Quan and Wang's structural model of the tourist experience: A Zimbabwean netnography of food tourism». Tourism Management Perspectives, 5, 68-74. <http://dx.doi.org/10.1016/j.tmp.2012.10.007>

Moyes, A. (2010). Cuina i terra de la Vall de Boí. Barcelona: Meteora.

Norberg, H. (2006). «De la dependencia mundial a la interdependencia local». A: Colectivo Revista Silence. Objetivo decrecimiento: ¿Podemos seguir creciendo hasta el infinito en un planeta finito? Barcelona: Leqtor, 79-137.

Padín, C. (2009). "Las fiestas gastronómicas en Galicia». A: Pardellas de Blas, X. (dir.). Turismo gastronómico: Recursos e itinerarios. Vigo: Universidade de Vigo, $135-150$.

Pearce, P. (1990). «Farm tourism in New Zealand: A social situation analysis». Annals of Tourism Research, 17, 337-352. <http://dx.doi.org/10.1016/0160-7383(90)90002-9>

QUAN, S. i WANG, N. (2004). "Towards a structural model of the tourist experience: An illustration from food experiences in tourism». Tourism Management, 25, 297-305. <http://dx.doi.org/10.1016/s0261-5177(03)00130-4>

Reynolds, P. (1994). "Culinary heritage in the face of tourism». Progress in Tourism, Recreation and Hospitality Management, 6, 189-194.

Richards, G. (2002). "Gastronomy: An essential ingredient in tourism production and consumption?». A: Hjalager, A. M. i Richards, G. (eds.). Tourism and gastronomy. Londres: Routledge, 3-20.

Royo, M. (2011). «El producto agroalimentario como atributo de importancia en la formación de la imagen del destino turístico». A: Flavian, C. i Fandos, C. (coords.). Turismo gastronómico: Estrategias de marketing y experiencias de éxito. Saragossa: Prensas Universitarias, 69-92.

Scarpato, R. (2002). "Gastronomy as a tourist product: The perspective of gastronomy studies». A: HJalager, A. M. i Richards, G. (eds.). Tourism and gastronomy. Londres: Routledge, 51-70.

Telfer, D. J. i Wall, G. (1996). «Linkages between Tourism and Food production». Annals of Tourism Research, 23 (3), 635-653. <http://dx.doi.org/10.1016/0160-7383(95)00087-9> 
- (2000). «Strengthening backward economic linkages: Local food purchasing by three Indonesian hotels». Tourism Geographies, 2 (4), 421-447. <http://dx.doi.org/10.1080/146166800750035521>

Torres, M. i Pulido, J. I. (2009). «Pautas para la creación de itinerarios turísticos de base gastronómica: Casos en Andalucía». A: Pardellas de Blas, X. (dir.). Turismo gastronómico: Recursos e itinerarios. Vigo: Universidade de Vigo, 11-30.

Tresserras, J. (2009). "Turismo de sol y playa y cocinas litorales: En busca de la calidad». A: Pardellas de Blas, X. (dir.). Turismo gastronómico: Recursos e itinerarios. Vigo: Universidade de Vigo, 107-116.

Tresserras, J. i Medina, F. X. (2008). Patrimonio gastronómico y turismo cultural en el Mediterráneo. Barcelona: Ibertur.

URry, J. (1990). The Tourist Gaze: Leisure and Travel in Contemporary Societies. Londres: Sage.

WANG, N. (1999). «Rethinking authenticity in tourism». Annals of Tourism Research, 26 (2), 349-370.

<http://dx.doi.org/10.1016/s0160-7383(98)00103-0> 